\title{
100 Anos de Química em Portugal Celebrados em Braga - XXII Encontro Nacional da SPQ
}

Entre 3 e 6 de Julho decorreu, no Parque de Exposições de Braga (PEB), o XXII Encontro Nacional da Sociedade Portuguesa de Química (XXII ENS$P Q$ ), organizado pelo Departamento de Química da Universidade do Minho (UMinho) e pela Delegação de Braga da SPQ. Esta edição do Encontro Nacional, inserindo-se nas comemorações do Centenário da SPQ, e sendo subordinada ao tema "Cem Anos de Química em Portugal”, teve uma elevada adesão, contando com a presença de 600 participantes.

Ao XXII ENSPQ associaram-se o $10^{\circ}$ Encontro de Química dos Alimentos, o $7^{\circ}$ Encontro Nacional de Química Analítica, o $10^{\circ}$ Encontro Nacional de Química Física, a $9^{a}$ Conferência de Química Inorgânica, o $9^{\circ}$ Encontro Nacional de Química Orgânica e o $8^{\circ}$ Encontro do Grupo de Radicais Livres.

A cerimónia de abertura contou com a presença de diversas individualidades, nomeadamente a Vice-Reitora da UMinho, Prof. ${ }^{a}$ Doutora Graciete Dias, a Vice-Presidente da Escola de Ciências da UMinho, Prof. ${ }^{a}$ Doutora Fernanda Proença (Figura 1), o Director do Departamento de Química da

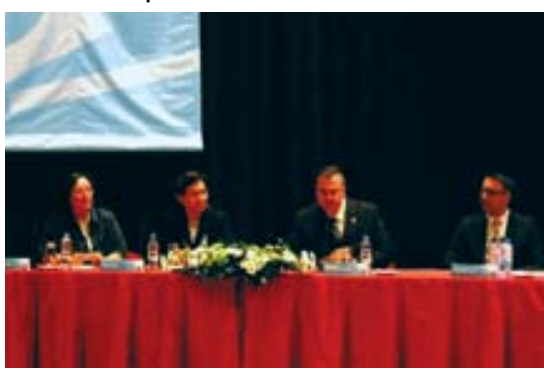

Figura 1 - Mesa da sessão de abertura. Da esquerda para a direita: Professora Fernanda Proença, Professora Graciete Dias, Professor Mário Berberan e Santos e Presidente da Comissão Organizadora

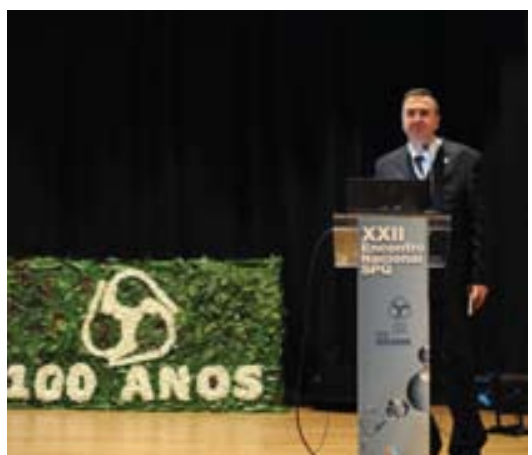

Figura 2 - Professor Mário Berberan e Santos durante o seu discurso

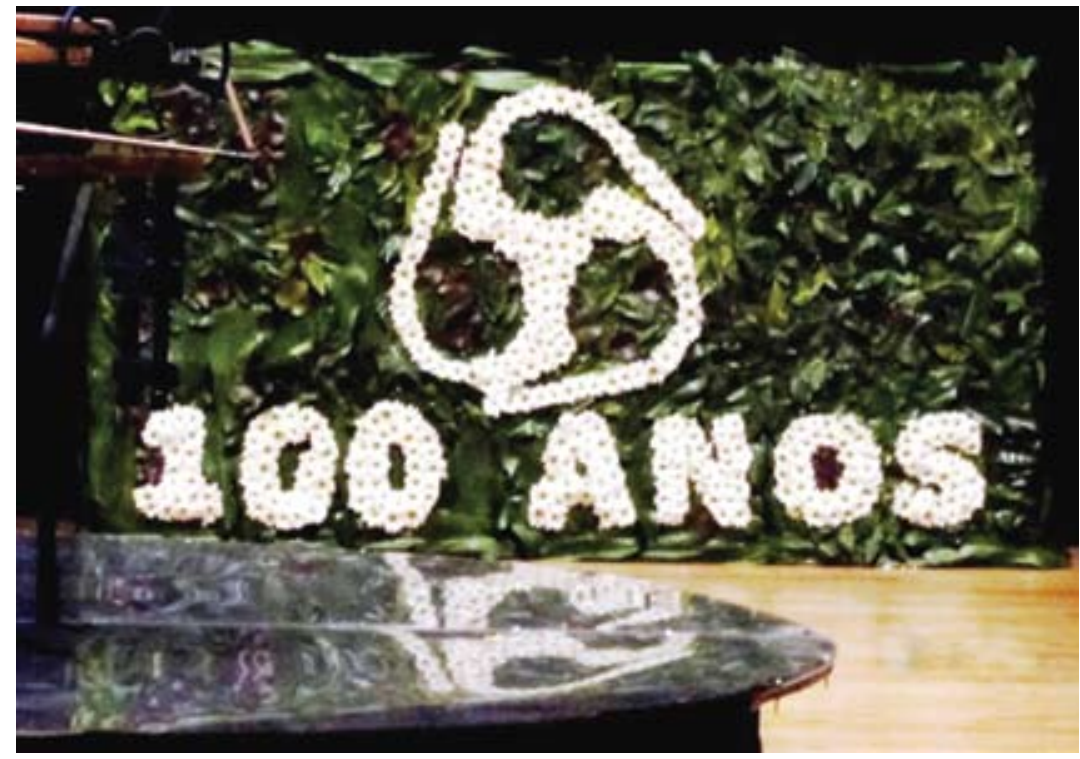

UMinho, Prof. Doutor Michael Smith, a Presidente do Centro de Química da UMinho, Doutora Maria João Queiroz, o Vice-Presidente da Câmara Municipal de Braga, Dr. Vítor Amaral de Sousa, o Presidente da Adere-Minho, Eng. Abílio Vilaça e o AdministradorExecutivo do PEB, Dr. Jorge Miguel Corais. Após uma breve sessão de cumprimentos por parte do Presidente da Comissão Organizadora, o Presidente da SPQ, Prof. Doutor Mário Berberan e Santos proferiu o discurso de abertura (Figura 2), a que se seguiu a lição plenária histórica pelo Prof. Doutor Sebastião Formosinho, da Universidade de Coimbra, intitulada 100 Anos da Química em Portugal sob os auspícios da "Sociedade Portuguesa de Química” (Figura 3). Esta foi seguida da plenária News from the Caparica photochemistry group. Chemistry is beautiful proferida pelo Prof. Doutor Fernando Pina, da Universida-

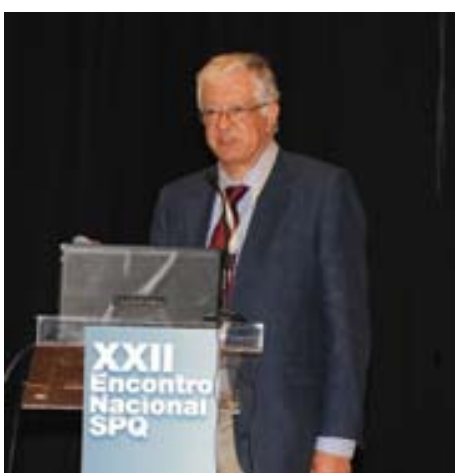

Figura 3 - Professor Sebastião Formosinho durante a sua lição plenária de Nova de Lisboa, recipiente do Prémio Ferreira da Silva 2010 (Figura 4).

O primeiro dia do XXII ENSPQ continuou com um recital de árias e duetos de ópera (Figura 5), a que se seguiram um "Verde de Honra" e a peça Maria Curie de Mira Michalowska, interpretada pelo Teatro Extremo (Figura 6).

Neste primeiro dia do Encontro funcionou no PEB um posto dos CTT onde era possível adquirir o Inteiro Postal do XXII ENSPQ/100 Anos SPQ com o respectivo carimbo comemorativo (Figura 7).

O segundo dia do Encontro teve início com a lição plenária de Sir Thomas Blundell, da Universidade de Cambridge, Genomes, structural biology and drug discovery: opportunities for academia and industry. A sessão da tarde começou com a lição plenária do

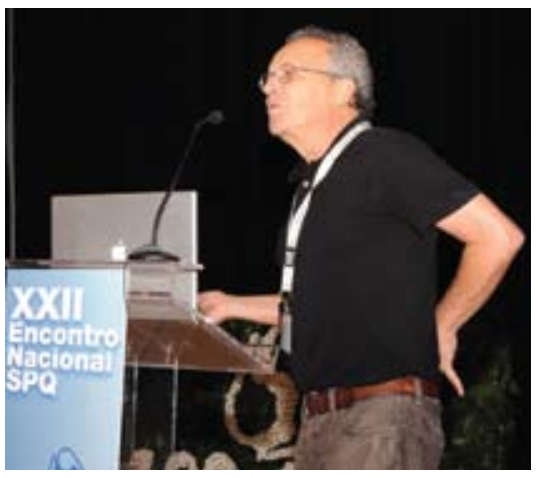

Figura 4 - Professor Fernando Pina Prémio Ferreira da Silva 2010 


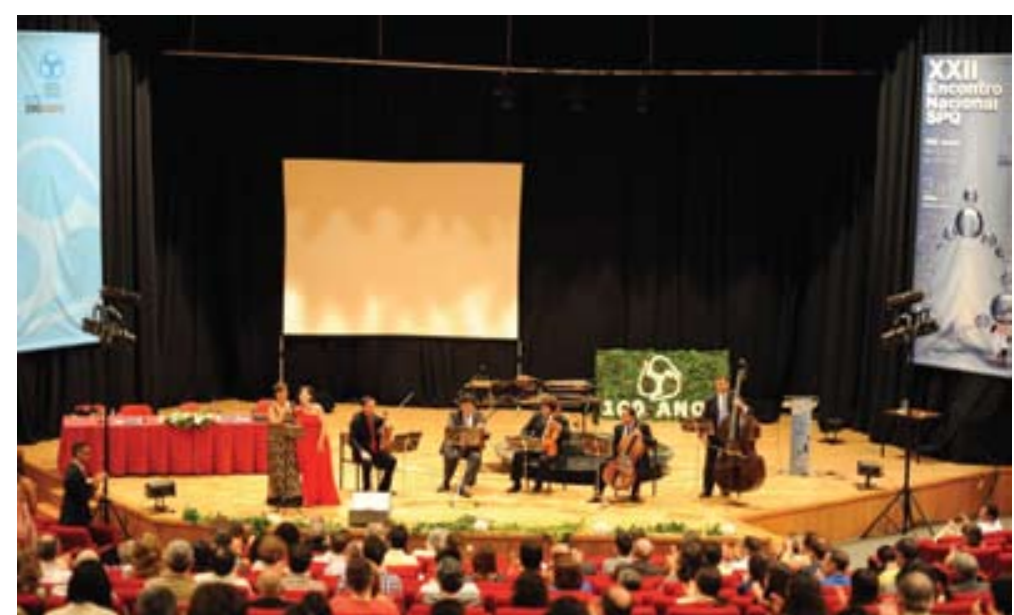

Figura 5 - Ana Sêrro e Natália de Carvalho Brito interpretando árias e duetos de ópera acompanhadas pelo Quinteto Intempore

Prof. Doutor Jorge Rodriguez Navarro, da Universidade de Granada, Robust metal organic frameworks for the separation and purification of gases.

No terceiro dia assistiu-se às lições plenárias do Prof. Doutor Agílio Pádua, da Universidade Blaise Pascal, Ionic Liquids: molecular interactions, solvation, interfaces e do Prof. Doutor Werner Pfannhauser da Universidade Técnica de Graz, Developments in food analysis. Neste dia procedeu-se pela primeira vez à entrega do Prémio Romão Dias, para a área da Química Inorgânica. A galardoada, Prof. ${ }^{a}$ Doutora Maria José Calhorda, da Univer-

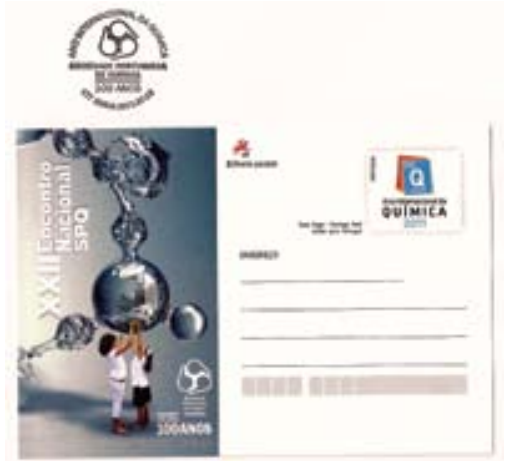

Figura 7 - Inteiro Postal e carimbo comemorativos do XXII ENSPQ/100 Anos SPQ

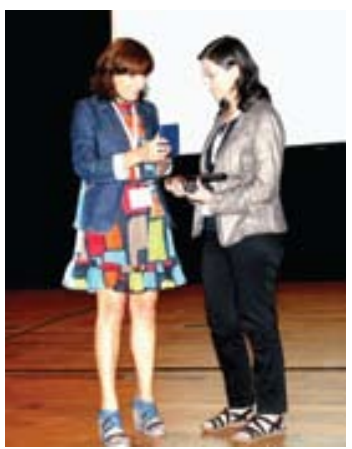

Figura 8 - A Professora Maria José Calhorda recebe o Prémio Romão Dias das mãos da Presidente da Divisão de Química Inorgânica sidade de Lisboa, proferiu na ocasião a lição plenária Química organometálica: uma vida... (Figura 8). O dia reservava ainda tempo para o convívio informal entre os participantes com um passeio ao Mosteiro de Tibães (Figura 9) e o Jantar do Encontro (Figura 10).

O quarto, e último dia, teve início com a lição plenária do Prof. Doutor Mehran Mostafavi, da Universidade de Paris-Sud, Nanoparticles of metal and semiconductor, the contribution of radiation chemistry. Após o almoço teve lugar a Mesa Redonda "Prémio Ferreira da Silva" que reuniu alguns dos recipientes deste galardão: Prof. Doutor Jorge Calado (1982), Prof. Doutor Manuel Ribeiro da Silva (2002), Prof. Doutor José Martinho Simões (2006) e Prof. Doutor Fernando Pina (2010). Foram moderadores Vânia Calisto, Mariana Sardo, Sérgio Santos (Grupo de Químicos Jovens da SPQ) e Paula Nogueira (Figura 11).

A última lição plenária do Encontro, NMR as a research tool: from molecular structure to molecular imaging, foi apresentada pelo Prof. Doutor Carlos Geraldes da Universidade de Coimbra. Seguiu-se a entrega da Medalha Vicente de Seabra 2010 ao Doutor

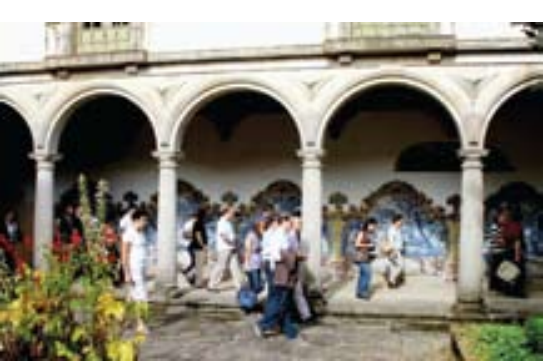

Figura 9 - Claustro do Mosteiro de Tibães

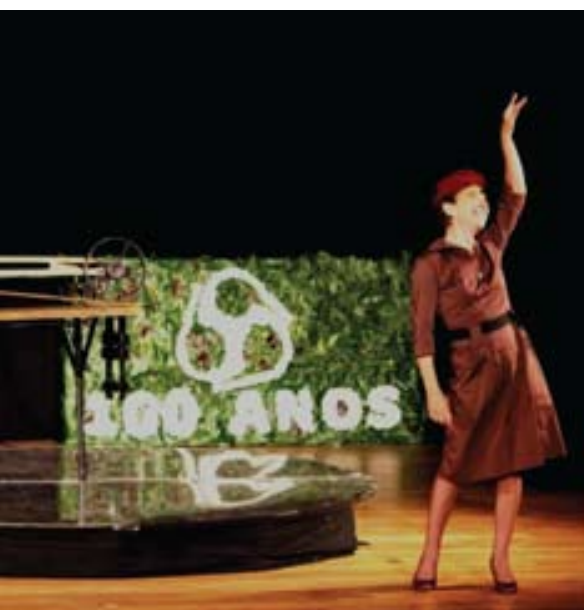

Figura 6 - Isabel Leitão na peça Maria Curie

Eurico Cabrita (Figura 12), da Universidade Nova de Lisboa, e ao Doutor José Richard Gomes (Figura 13), da Universidade de Aveiro. Os títulos das suas comunicações orais foram respectivamente In resonance with chemistry e Exploring mechanisms of chemical reactions at surfaces.

O XXII ENSPQ contou ainda com 34 comunicações orais convidadas (keynotes), 82 comunicações orais, nas áreas científicas das Divisões e do Grupo associados ao Encontro e ainda nos domínios de Química e Sociedade e Ensino e Aprendizagem da Química. Contou igualmente com duas sessões de posters (Figura 14), onde foram apresentadas 383 comunicações.

Durante o Encontro esteve patente a exposição Vida e Obra de Maria Skłodowska-Curie do Museu Maria Skłodowska-Curie de Varsóvia, numa versão Portuguesa da Comissão do Departamento de Química da UMinho para o Ano Internacional da Química (AIQ). Estiveram também expostas as peças de artesanato do concurso INOVARTE 2011, promovido pela Adere-Minho e que teve como tema

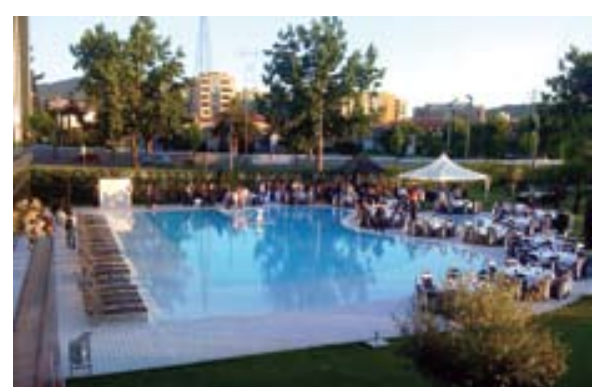

Figura 10 - Perspectiva do local do Jantar do Encontro 
o AIQ. Um artesão trabalhou a prata durante os vários dias do Encontro (Figura 15).

O XXII ENSPQ teve o apoio de várias instituições (FCT, PEB e Câmara Municipal de Braga) e de diversas empresas, algumas das quais marcaram presença. De referir ainda a sessão de autógrafos da Prof. ${ }^{a}$ Doutora Raquel Gonçalves-Maia, por ocasião do lançamento da sua mais recente obra
Marie Skłodowska-Curie - Imagens de outra face, e a do Prof. Doutor Jorge Calado cuja obra Haja Luz! Uma história da Química através de tudo foi publicada recentemente.

A sessão de encerramento do XXII ENSPQ contou com as intervenções do Secretário-Geral da SPQ, Doutor Joaquim de Faria, e do Presidente da Comissão Organizadora que apresentou alguns dados estatísticos do evento (Figura 16). Antes da partida, ao som de gaiteiros serviu-se o bolo do Centenário (Figura 17) e brindouse à SPQ (Figura 18).

As fotos do Encontro estão disponíveis em http://www.spq.pt/eventos/ xxiienspq/.

João Paulo André

(jandre@quimica.uminho.pt) Presidente da Comissão Organizadora do XXII ENSPQ

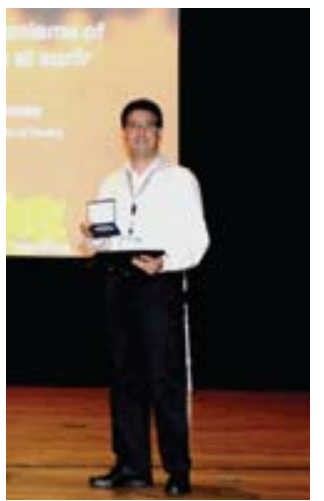

Figura 12 - Doutor Eurico Cabrita Medalha Vicente de Seabra 2010

Figura 13 - Doutor José Richard Gomes Medalha Vicente de Seabra 2010

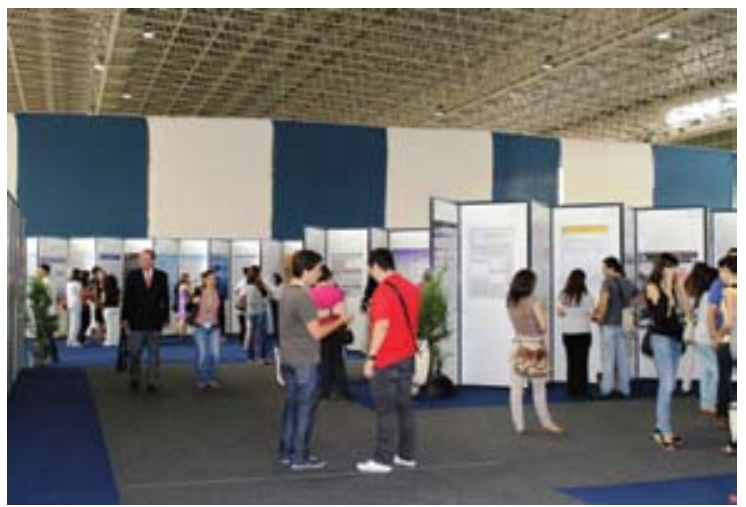

Figura 14 - Aspecto das sessões de posters

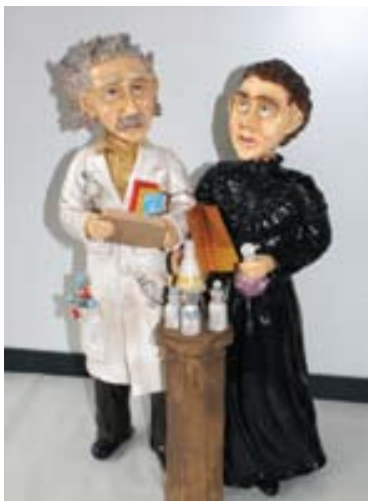

Figura 15 - Obra vencedora do concurso INOVARTE 2011, Einstein com Marie Curie, da autoria do artesão Manuel Macedo

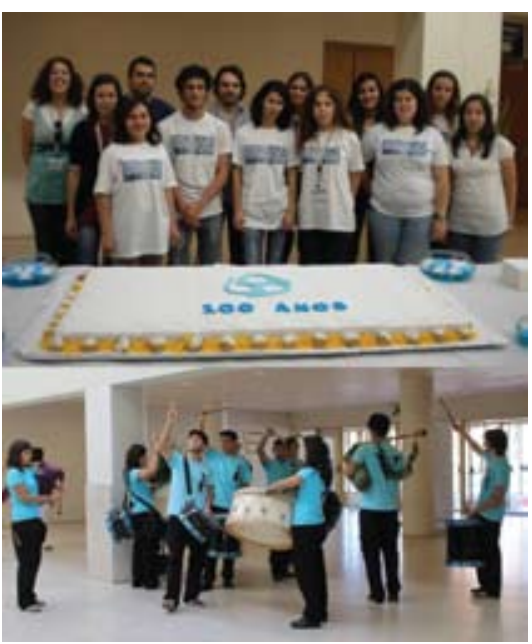

Figura 17 - Bolo do Centenário, gaiteiros alguns dos estudantes que colaboraram com a Comissão Organizadora

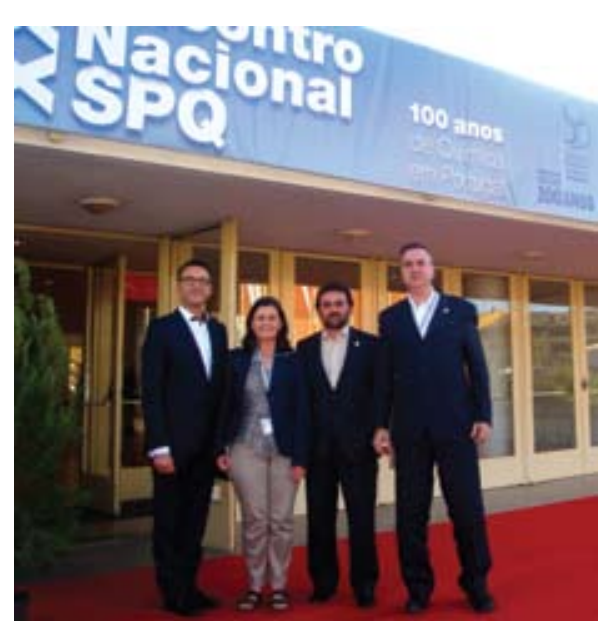

Figura 18 - Direcção da SPQ e Presidente da Comissão Organizadora
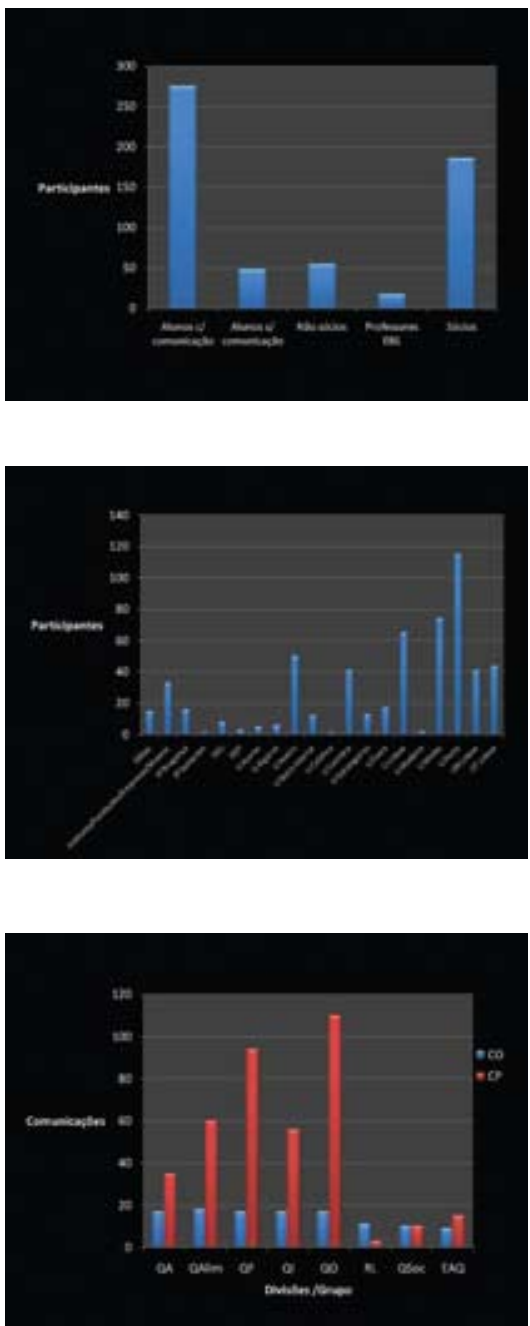

Figura 16 - Dados estatísticos da participação no XXII ENSPQ 